\title{
Sebaran Generalized Extreme Value (GEV) dan Generalized Pareto (GP) untuk Pendugaan Curah Hujan Ekstrim di Wilayah DKI Jakarta
}

\author{
Achi Rinaldi \\ IAIN Raden Intan Lampung; achi_rinaldi@yahoo.co.uk
}

\begin{abstract}
Extreme event such as extreme rainfall have been analyzed and most concern for the country all around the world. There are two common distribution for extreme value which are Generalized Extreme Value distribution and Generalized Pareto distribution. These two distribution have shown good performace to estimate the parameter of extreme value. This research was aim to estimate parameter of extreme value using GEV distribution and GP distribution, and also to characterized effect of extreme event such as flood. The rainfall data was taken from BMKG for 5 location in DKI Jakarta. Both of distribution shown a good perfromance. The resut showed that Tanjung Priok station has biggest location parameter for GEV and also the biggest scale parameter for GP, that mean the biggest probability to take flood effect of the extreme rainfall.
\end{abstract}

Keyword: Extreme event; Generalized Extreme Value; Generalized Pareto.

\begin{abstract}
Abstrak
Kejadian ekstrem seperti curah hujan ekstrem telah dianalisis dan sangat memprihatinkan bagi negara di seluruh dunia. Ada dua distribusi umum untuk nilai ekstrim yaitu distribusi Generalized Extreme Value dan distribusi Genereto Pareto. Kedua distribusi ini telah menunjukkan kinerja yang baik untuk memperkirakan parameter nilai ekstrim. Penelitian ini bertujuan untuk memperkirakan parameter nilai ekstrim dengan menggunakan distribusi Gev dan distribusi GP, dan juga untuk karakteristik efek kejadian ekstrim seperti banjir. Data curah hujan diambil dari BMKG untuk 5 lokasi di DKI Jakarta. Kedua distribusi menunjukkan perfromance yang baik. Hasil resut menunjukkan bahwa stasiun Tanjung Priok memiliki parameter lokasi terbesar untuk GEV dan juga parameter skala terbesaruntuk GP, yang berarti probabilitas terbesar untuk mengambil pengaruh banjir dari curah hujan ekstrem.
\end{abstract}

Keyword: Extreme event; Generalized Extreme Value; Generalized Genereto.

\section{PENDAHULUAN}

Kejadian ekstrim memberikan pengaruh yang signifikan terhadap kehidupan manusia, contoh dari kejadian ekstrim tesebut adalah: badai, gelombang panas, banjir, musim kemarau yang berkepanjangan dan lain-lain. Kesulitan utama dalam menganalisis fenomena kejadian ekstrim seperti curah hujan ekstrim adalah sifatnya yang kompleks dan sulit ditebak, kejadian maupun intensitasnya yang tidak teratur, keheterogenan spatial serta secara sementara dapat menyesuaikan terhadap keragaman peubah iklim. Lebih lanjut, fenomena kejadian ekstrim merupakan fenomena yang sangat langka sesuai dengan definisinya, ini mengakibatkan 
ketersediaan data juga sangat minim. Penggunaan teori nilai ekstrim merupakan alat yang tepat untuk menyesuaikan keterbatasan data yang ada. Untuk pertama kalinya Fisher dan Tippett (1928) memperkenalkan teori mengenai sebaran nilai ekstrim, kemudian Gnedenko (1943) mengembangkan teori sebaran ekstrim dengan membuktikan secara matematis bahwa dalam kondisi tertentu keluarga sebaran dari Gumbel, Frechet, dan Weibull dapat mendekati sebaran dari nilai ekstrim untuk contoh acak. Penggabungan dari keluarga sebaran Gumbel, Frechet, dan Weibull dikenal dengan nama sebaran Generalized Extreme Value (GEV). Berdasarkan teori sebaran nilai ekstrim ini Gumbel (1942) menggunakannya untuk menganalisis kejadian banjir, lebih jauh lagi Gumbel (1958) menggunakan sebaran GEV untuk dimanfaatkan dalam beberapa bidang penerapan.

Saat ini dikenal ada dua pendekatan yang sering digunakan pada model kejadian ekstrim, yaitu metode Block Maxima (BM) dan metode Peak Over Threshold (POT). Metode BM merupakan metode yang mengidentifikasi nilai ekstrim melalui nilai maksimum dari data pengamatan yang dikelompokkan pada suatu blok atau periode tertentu. Pendekatan ini hanya menghasilkan satu nilai ekstrim pada setiap blok, sedangkan metode POT merupakan pendekatan yang mengidentifikasi nilai ekstrim melalui data pengamatan yang melebihi suatu nilai batas (threshold) tertentu. Sehingga pada metode POT akan dihasilkan satu atau lebih nilai ekstrim pada suatu blok atau periode tertentu. Pendekatan POT ini memberikan solusi dari segi keefisienan dari data karena lebih banyak data yang terambil sehingga bisa digunakan untuk memodelkan nilai ekstrim sekalipun data yang dipunyai jumlahnya sangat terbatas.

Metode Block Maxima (BM) mengacu pada sebaran GEV sedangkan metode Peak Over Threshold (POT) mengacu pada sebaran Generalized Pareto (Coles, Improving the analysis of extreme wind speeds with information sharing models, 2001). Sebaran Generalized Pareto (GP) diperkenalkan oleh Pickands (1975) sebagai sebaran yang memiliki dua parameter. Sebaran ini telah banyak dipakai secara luas oleh para peneliti seperti yang dilakukan oleh (Hosking \& Wallis, 1987) serta (Nelder \& Mead, 1965. ) yang meneliti tentang frekuensi kejadian ekstrim yaitu banjir. Mereka menyarankan penggunaan sebaran GP sebagai sebaran yang digunakan untuk menganalisis kejadian ekstrim.

Penelitian ini bertujuan membandingkan pendugaan parameter dari sebaran GEV dan GP dalam menduga curah hujan ekstrim menggunakan metode BM dan POT. Selanjutnya dilihat karakteristik dari masing-masing penduga sebaran untuk diaplikasikan dalam pendugaan curah hujan di wilayah DKI Jakarta.

\section{METODE PENELITIAN}

\section{Teori Nilai Ekstrim}

Teori nilai ekstrim bertujuan untuk mengkaji perilaku stokastik suatu proses pada suatu nilai ambang tertentu. Analisis ini juga memungkinkan untuk menaksir peluang suatu kejadian melebihi nilai ambang. Kejadian yang melebihi nilai ambang disebut kejadian ekstrim. Dalam pemodelan nilai maksimum dari suatu peubah acak, teori nilai ekstrim menyerupai teori limit pusat (central limit theorem) dalam memodelkan jumlah peubah acak yang diinginkan.

Misal $Y_{1}, Y_{2}, \ldots, Y_{n}$ merupakan peubah acak yang saling bebas dan memiliki fungsi sebaran identik $\mathrm{F}(\mathrm{y})$, sedangkan $M_{n}=\max \left(Y_{1}, Y_{2}, \ldots, Y_{n}\right)$ yang merupakan nilai 
maksimumnya. Jika $M_{n}$ konvergen ke salah satu limit non-degenerate, maka limit tersebut merupakan anggota keluarga parametrik, yaitu jika terdapat konstanta $a_{n}>0$, dan bn maka:

$$
\lim _{n \rightarrow \infty} P\left(\frac{M_{n}-b_{n}}{a_{n}} \leq y\right)=\lim _{n \rightarrow \infty} F^{n}\left(a_{n} y+b_{n}\right)=G(y),
$$

dengan $\mathrm{G}$ adalah fungsi sebaran non-degenerate. Fungsi sebaran $\mathrm{G}$ tersebut akan mengikuti salah satu dari tiga sebaran dasar nilai ekstrim. Ketiga bentuk sebaran yang dimaksud adalah sebaran Gumbel, sebaran Frechet, dan sebaran Weibull, dengan persamaan masing-masing:

Gumbel: $G(y)=\exp \left\{-\exp \left[-\left(\frac{y-b}{a}\right)\right]\right\} ;-\infty<y<\infty$

Frechet: $G(y)= \begin{cases}0 & ; y \leq a \\ \exp \left\{-\left(\frac{y-b}{a}\right)^{-\alpha}\right\} & ; y>a\end{cases}$

Weibull: $\quad G(y)= \begin{cases}\exp \left\{-\left[-\left(\frac{y-b}{a}\right)\right]^{\alpha}\right\} & ; y<a \\ 1 & ; y \geq a\end{cases}$

dengan $a>0$ adalah parameter skala, $b$ adalah parameter lokasi dan $\alpha$ adalah parameter bentuk.

Ketiga sebaran ini memiliki bentuk ujung sebaran yang berbeda, sebaran Weibull memiliki ujung sebaran yang terhingga sedangkan sebaran Gumbel dan Frechet memiliki ujung sebaran yang tak terhingga. Selain itu, fungsi peluang $\mathrm{G}$ untuk sebaran Gumbel menurun secara eksponensial dan untuk sebaran Frechet menurun secara polinomial. Kurva dari ketiga sebaran ekstrim tersebut dapat dilihat pada Gambar 2. Perbedaan ujung sebaran dari ketiga sebaran memberikan gambaran yang berbeda untuk perilaku nilai ekstrim, sehingga sulit untuk menentukan secara tepat pola sebaran dari nilai ekstrim. Permasalahan ini dapat diselesaikan dengan menggabungkan ketiga tipe sebaran ke dalam sebaran nilai ekstrim terampat (generalized extreme value/GEV) sebagai berikut:

$$
G(y)=\left\{\begin{array}{l}
\exp \left\{-\left(1+\xi \frac{y-\mu}{\sigma}\right)^{-1 / \xi}\right\}, \xi \neq 0 \\
\exp \left\{-\exp \left(-\frac{y-\mu}{\sigma}\right)\right\}, \quad \xi=0
\end{array}\right.
$$

dengan $\mu$ adalah parameter lokasi, $\sigma>0$ adalah parameter skala, sedangkan $\xi$ adalah parameter bentuk. Adapun parameter bentuk $\xi$ merupakan parameter yang menentukan karakteristik ujung sebaran, jika $\xi<0$ maka fungsi peluangnya mempunyai suatu titik ujung kanan yang terhingga dan jika $\xi \geq 0$ maka fungsi peluangnya akan mempunyai titik ujung kanan yang tak terhingga (Coles dan Tawn 1996). Bentuk sebaran GEV akan mengarah pada sebaran Gumbel untuk limit $\xi \rightarrow 0$, untuk sebaran Frechet jika $\xi>0$, dan untuk sebaran Weibull jika $\xi<0$. 


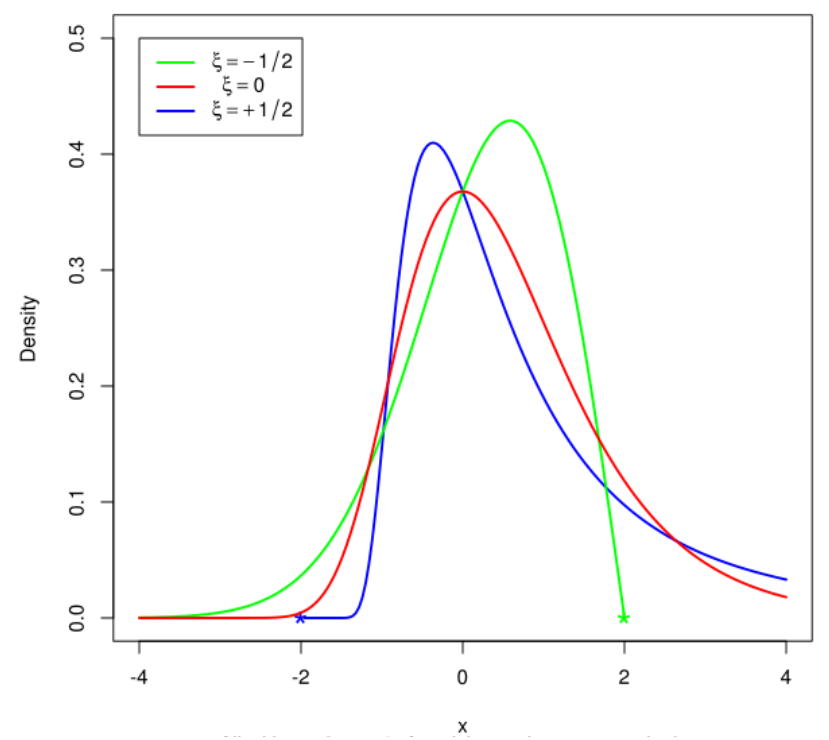

Gambar 1 Kurva sebaran nilai ekstrim dengan $\mu=0$ dan $\sigma=1$.

\section{Sebaran Generalized Pareto}

Sebaran GEV biasanya digunakan dalam pendekatan Block Maxima (BM), blok secara umum ditentukan oleh pembagi alami seperti tahun. Misalkan $y_{k i}$ adalah observasi ke-i dan dalam blok ke-k maka penentuan nilai maksimum per blok menjadi $M_{k}=\max \left(Y_{k 1}, \ldots, Y_{k n}\right)$. Kelemahan pada pendekatan Block Maxima pada nilai ekstrim adalah banyaknya data observasi yang terbuang karena hanya diambil satu nilai maksimum yang akan menjadi masalah jika ketersediaan data sangat minim atau terbatas. Untuk mengatasi permasalahan keterbatasan data maka ada cara lain yaitu dengan menentukan nilai ambang. Jika pengambilan nilai ekstrim diperoleh dari nilai yang melampaui ambang $u$, dengan $y-u>0$, data nilai ekstrim akan mengikuti sebaran Pareto Terampat (Generalized Pareto/GP) dengan fungsi sebaran:

$$
H(y)=\left\{\begin{array}{l}
1-\left(1-\frac{\xi y}{\tilde{\sigma}}\right)^{-1 / \xi} ; \xi \neq 0 \\
1-\exp \left(-\frac{y}{\tilde{\sigma}}\right) ; \xi=0
\end{array}\right.
$$

dengan y $>0$ dimana $\tilde{\sigma}=\sigma+\xi(u-\mu)$, y adalah nilai yang lebih dari nilai ambang batas $\mathrm{u}$ yang dirumuskan dengan $\mathrm{y}=\mathrm{z}-\mathrm{u}, \mathrm{z}$ adalah data pengamatan asli (Coles, 2011). Fungsi kepekatan peluang ( $\mathrm{fkp}$ ) dari GP, dengan menurunkan fungsi sebarannya, dapat dinyatakan sebagai berikut (Coles, Regional Modelling of Extreme Storms via Max-Stable Processes, 1993; Tawn, 1988; Coles \& Tawn, A Bayes analysis of extreme rainfall data, 1996):

$$
h(y)= \begin{cases}\frac{1}{\sigma} \exp \left(1+\frac{\xi}{\sigma} y\right)^{-1 / \xi^{-1}}, \xi \neq 0 \\ \frac{1}{\sigma} \exp \left(-\frac{y}{\sigma}\right) & , \xi=0 .\end{cases}
$$


Metode pendugaan kemungkinan maksimum adalah cara yang digunakan untuk menduga parameter GP.

\section{METODE PENELITIAN}

Data

Data yang digunakan adalah data sekunder yang diperoleh dari Badan Meteorologi Klimatologi dan Geofisika (BMKG). Data ini berupa data intensitas curah hujan harian di DKI Jakarta yang terdiri dari 5 stasiun amatan. Data curah hujan yang digunakan minimal mempunyai periode waktu 10 tahun sehingga diambil periode tahun 1985-2014. Adapun peubah-peubah yang terdapat dalam data curah hujan adalah: curah hujan (dalam milimeter/mm), koordinat bujur dan lintang, serta peubah ketinggian (elevasi).

\section{Identifikasi Data Esktrim dengan Blok Maksima}

Secara umum untuk menentukan nilai-nilai ekstrim dapat dilakukan dengan dua cara (Gilli \& Këllezi , 2006), yaitu:

1. Menentukan nilai-nilai maksimum dalam suatu periode, misalnya periode mingguan, bulanan atau tahunan, pengamatan dari nilai-nilai ini dianggap sebagai nilai ekstrim.

2. Mengambil nilai-nilai yang melampaui suatu nilai ambang (threshold) $u$, seluruh nilai-nilai yang melampaui nilai ambang $u$ dianggap sebagai nilai-nilai ekstrim.

Ketika sebaran ekstrim yang digunakan adalah sebaran $\operatorname{GEV}(\mu, \sigma, \xi)$, maka penentua n nilai ekstrim adalah dengan mengambil nilai maksimum dalam suatu periode. Sedangkan jika sebaran ekstrim yang digunakan adalah sebaran Pareto Terampat (Generalized Pareto Distribution / GPD) maka nilai-nilai yang mewakili nilai ekstrim adalah dengan mengambil nilai yang melampaui nilai ambang.

Untuk membentuk data ekstrim dengan blok maksima misalnya dalam kasus curah hujan ekstrim langkah yang diambil adalah menetapkan curah hujan harian atau bulanan ke dalam suatu blok dan mengasumsikan nilai maksimumnya saling bebas, sedangkan parameter dimodelkan dalam $\mu, \sigma$, dan $\xi$. Ini berarti setiap nilai maksimum di asumsikan mengikuti sebaran $\operatorname{GEV}(\mu, \sigma, \xi)$.

\section{Identifikasi Data Ekstrim dengan POT (Peak Over Threshold)}

Metode POT merupakan salah satualternatif untuk membangun suatu model ekstrim selain metode Block maxima. Kelemahan pada pendekatan Block Maxima pada nilai ekstrim adalah banyaknya data observasi yang terbuang karena hanya diambil satu nilai maksimum yang akan menjadi masalah jika ketersediaan data sangat minim atau terbatas. Untuk mengatasi permasalahan keterbatasan data maka metode Peak Over Threshold (POT) merupakan cara yang tepat.

Pemodelan menggunakan metode POT mengandung tiga komponen, yaitu:

1. Penentuan nilaiambang. 
2. Banyaknya kejadian nilai yang melebihi ambang.

3. Nilai-nilai yang melebihi ambang memiliki sebaran GP.

Menurut Coles (2001), pemilihan nilai ambang u dalam sebaran GPD dapat menggunakan Mean Residual Life Plot (MRLP). Metode MRLP didasarkan pada rata-rata nilai ekstrim, jika Y menyebar GPD dengan parameter $\sigma$ dan $\xi$, maka

$E(Y)=\frac{\sigma}{1-\xi}$

untuk $\xi<1$, karena jika $\xi \geq 1$ maka rata-ratanya tak terhingga. Misal peubah acak Z merupakan pengamatan yang lebih dari nilai ambang batas $\mathrm{u} 0$ akan menyebar GPD dengan rata-rata sebagai berikut:

$E\left(Z-u_{0} \mid Z>u_{0}\right)=\frac{\sigma_{u_{0}}}{1-\xi}$

dimana $\xi<1$, sedangkan $\sigma_{u_{0}}$ adalah parameter skala pada untuk nilai ambang u0. Jika model sebaran GPD valid pada nilai ambang $u 0$, maka harus juga valid pada nilai ambang $u>$ $\mathrm{u0}$, oleh karena itu, nilai parameter skala akan berubah menjadi ou, sehingga nilai rata-ratanya adalah

$E\left(Z-u_{0} \mid Z>u_{0}\right)=\frac{\sigma_{u}}{1-\xi}=\frac{\sigma_{u_{0}}-\xi u}{1-\xi}$.

Misal $z(1), \ldots, z(k)$ adalah pengamatan yang melebihi nilai ambang batas u sebanyak $k$, dan zmax adalah nilai maksimum dari z(i), maka titik-titik untuk plot MRL adalah

$\left\{\left(u, \frac{1}{k} \sum_{i=1}^{k}\left(z_{i}-u\right)\right): u<z_{\max }\right\}$.

Plot MRL dilengkapi dengan selang kepercayaan. Selang kepercayaan pada plot MRL dapat dihitung melalui pendekatan normal dari rataan contoh. Pemilihan titik pada MRL sebagai nilai ambang batas adalah dengan cara melihat nilai u yang mendekati linier. Pendugaan parameter baik dari sebaran GEV maupun sebaran GP menggunakan program $\mathrm{R}$ dengan versi 3.1.1 melalui paket ismev (introduction to statistical modelling of extreme value) yang direkomendasikan oleh (Coles, Improving the analysis of extreme wind speeds with information sharing models, 2001).

\section{HASIL PENELITIAN DAN PEMBAHASAN}

\section{Pendugaan Parameter Sebaran GEV}

Sebelum dilakukan pendugaan parameter, maka terlebih dahulu dilakukan identifikasi nilai ekstrim dengan metode Blok Maksima, dimana dicari nilai maksimum curah hujan harian pertahun (milimeter/mm) yang dapat dilihat pada tabel 1. 
Tabel 1 Curah Hujan Maksimum Pertahun

\begin{tabular}{rrrrrr}
\hline Tahun & P. Betung & Kemayoran & Soekarno Hatta & Tangerang & Tj. Priok \\
\hline 1985 & 107 & 148.3 & 64 & 85 & 106.7 \\
1986 & 173 & 94 & 175 & 70 & 114.9 \\
1987 & 170 & 98.8 & 189 & 191 & 106 \\
1988 & 101 & 356 & 101 & 104 & 100 \\
1989 & 86.4 & 80.5 & 86 & 85 & 100 \\
1990 & 134 & 58.6 & 83 & 85 & 215.6 \\
1991 & 122.8 & 139.5 & 98 & 130 & 180.4 \\
1992 & 129 & 98.3 & 116 & 126 & 170.8 \\
1993 & 103 & 101 & 136 & 91 & 178 \\
1994 & 93.8 & 92.6 & 85 & 105 & 98.2 \\
1995 & 128.9 & 75.7 & 80 & 200 & 103.2 \\
1996 & 129.5 & 216.2 & 107 & 175 & 102.1 \\
1997 & 94 & 125.6 & 103 & 119 & 118.3 \\
1998 & 123.5 & 162.2 & 108 & 86.5 & 110.9 \\
1999 & 111 & 147.2 & 97 & 98 & 106 \\
2000 & 103.4 & 94.8 & 94.5 & 104 & 65.2 \\
2001 & 104 & 82.2 & 84.3 & 130 & 210 \\
2002 & 109.2 & 168.5 & 88 & 123 & 147.1 \\
2003 & 119.2 & 199.7 & 115 & 130 & 126.7 \\
2004 & 94 & 129.3 & 114.5 & 84 & 121.4 \\
2005 & 104.5 & 124.1 & 158.1 & 82 & 109.9 \\
2006 & 79.3 & 72 & 61.5 & 63 & 90.3 \\
2007 & 339.8 & 234.7 & 153.2 & 98 & 182.2 \\
2008 & 209 & 192.7 & 316.3 & 286 & 87.9 \\
2009 & 114 & 122.5 & 106.7 & 96 & 148.9 \\
2010 & 108.9 & 93 & 106.2 & 76 & 88.3 \\
2011 & 61.9 & 119.2 & 75.5 & 97.7 & 78.5 \\
2012 & 79.8 & 105.2 & 101.1 & 72.5 & 75.1 \\
2013 & 96 & 193.4 & 397.4 & 100.5 & 117.8 \\
2014 & 119.5 & 147.9 & 104.1 & 117.5 & 154.1
\end{tabular}

Hasil output dari pendugaan parameter GEV adalah sebagai berikut: 
Tabel 2 Nilai Parameter GEV Setiap Stasiun Hujan

\begin{tabular}{crrrrc}
\hline Parameter & P. Betung & Kemayoran & Soekarno Hatta & Tangerang & Tj. Priok \\
\hline$\mu$ & 99.52144 & 101.61807 & 93.572316 & 91.542322 & 102.9206 \\
$\sigma$ & 26.33619 & 34.6299008 & 26.7787821 & 22.148901 & 27.51658 \\
$\xi$ & 0.1645 & 0.2240001 & 0.3379181 & 0.2712978 & 0.111379 \\
\hline
\end{tabular}

Analisis data untuk semua stasiun memiliki nilai parameter bentuk $\xi>0$, berarti fungsi peluangnya sama untuk setiap stasiun dan memiliki titik ujung kanan yang tak terhingga. Mengindikasikan berpeluang besar menjadi curah hujan ekstrim kanan, atau ekstrim basah yang dapat menyebabkan banjir. Sedangkan untuk parameter $\mu$ yang memiliki nilai tertinggi adalah di Stasiun Tj. Priok yang berarti peluang paling tinggi untuk terjadi banjir adalah di daerah utara Jakarta khususnya Tanjung Priok. Hal ini selaras dengan data-data yang ada mengenai intensitas banjir yang sering terjadi di kawasan tersebut.

\section{Pendugaan Parameter Sebaran GP}

Sebelum dilakukan pendugaan parameter, maka terlebih dahulu dilakukan identifikasi nilai ekstrim dengan metode POT, dimana dicari nilai ambang yang dapat dilihat pada gambar 2 grafik MRLP .
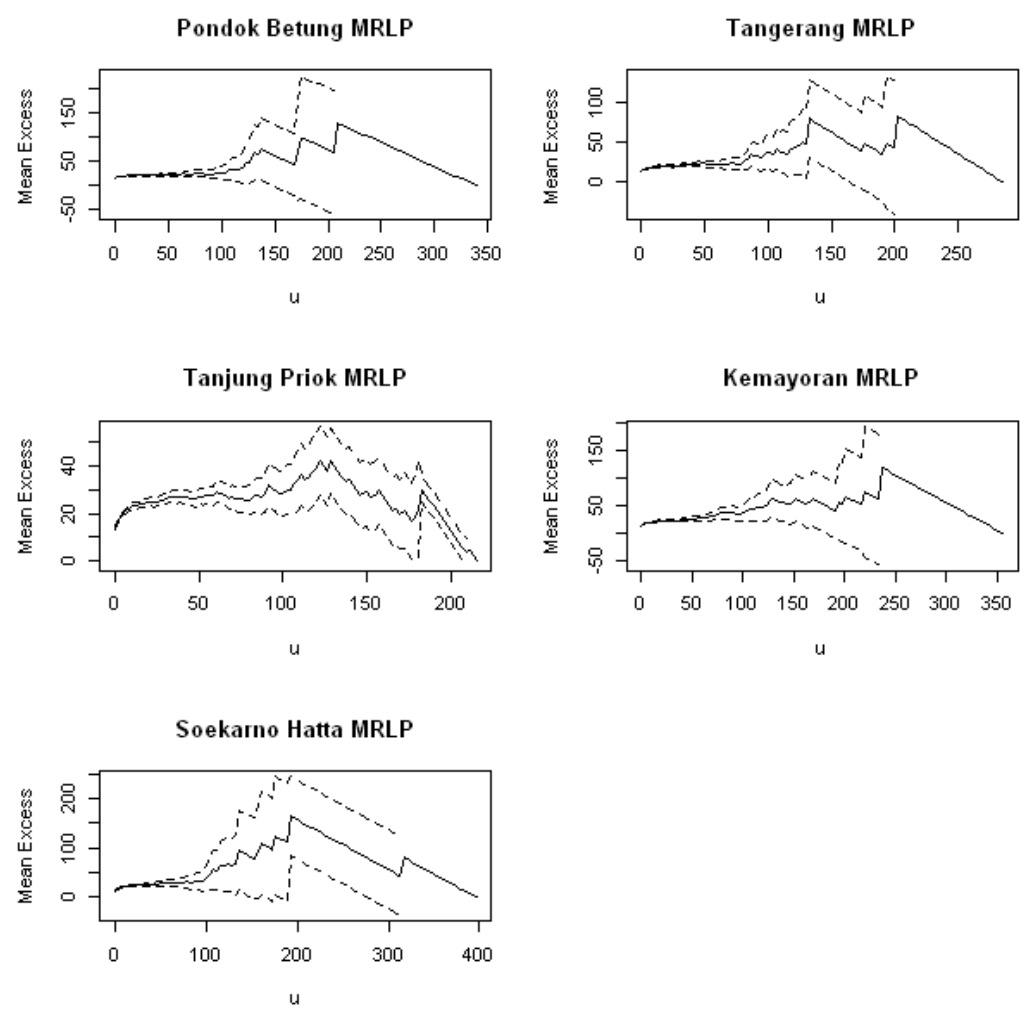
Dari gambar Mean Residual Life Plot (MRLP) yang ada terlihat nilai ambang atau threshold untuk setiap stasiun hujan berbeda-beda. Ini menandakan bahwa untuk setiap daerah memiliki nilai pemicu banjir yang berbeda-beda. Stasiun Pondok Betung terlihat nilai ambangnya di sekitar $70 \mathrm{~mm}$, Stasiun Tangerang $60 \mathrm{~mm}$, Tanjung Priok $50 \mathrm{~mm}$, Kemayoran $100 \mathrm{~mm}$, sedangkan untuk Soekarno Hatta $70 \mathrm{~mm}$. Dapat disimpulkan bahwa daerah yang paling rawan banjir adalah Jakarta Utara khususnya di Tanjung Priok, ini dikarenakan nilai ambangnya memiliki nilai yang terendah yaitu $50 \mathrm{~mm}$. Jika terjadi hujan di atas $50 \mathrm{~mm}$ maka akan berpeluang besar terjadi banjir di wilayah tersebut. Bertolak belakang dengan Stasiun Kemayoran yang memiliki nilai ambang tinggi yaitu 100 mm, jika Tanjung Priok berpeluang besar terjadi banjir untuk curah hujan $>50 \mathrm{~mm}$ maka Kemayoran berpeluang kecil untuk terjadi banjir. Kemayoran akan berpeluang terjadi banjir jika curah hujan terjadi di atas 100 $\mathrm{mm}$.

Setelah dilakukan penentuan nilai ambang, maka langkah selanjutnya menduga nilai parameter dari sebaran Generalized Pareto. Nilai dari pendugaan parameter GP dapat dilihat pada tabel 3.

Tabel 3 Penduga Parameter Sebaran GP

\begin{tabular}{ccc}
\hline Stasiun Hujan & Parameter $\sigma$ & Parameter $\xi$ \\
\hline P. Betung & 20.4403401 & 0.1490896 \\
Tangerang & 19.5076470 & 0.1496047 \\
Tanjung Priok & 26.3623930 & 0.0297194 \\
Kemayoran & 26.2666254 & 0.3498884 \\
Soekarno Hatta & 21.153324 & 0.253041 \\
\hline
\end{tabular}

Dapat dilihat pada tabel 3 bahwa nilai dugaan parameter $\sigma$ tertinggi dimiliki oleh Stasiun Tanjung Priok, sedangkan yang terendah adalah Tangerang. Untuk parameter $\xi$ nilai tertinggi di Stasiun Kemayoran dan yang terendah di Stasiun Tanjung Priok. Ini sejalan dengan eksplorasi nilai ambang sebelumnya, yang dapat disimpulkan bahwa daerah yang paling rawan terhadap banjir adalah Tanjung Priok di banding stasiun lainnya.

\section{SIMPULAN DAN SARAN}

Secara umum kedua sebaran baik sebaran Generalized Extreme Value (GEV) maupun Generalized Pareto (GP) memberikan hasil yang baik dan cenderung selaras untuk nilai dugaan curah hujan ekstrim. Untuk penduga parameter $\xi$ kedua sebaran menunjukkan stasiun Tanjung Priok yang memiliki nilai terendah. Sedangkan parameter $\mu$ pada sebaran GEV menunjukan nilai tertinggi ada di Stasiun Tanjung Priok. Untuk nilai ambang, nilai terendah terdapat di Stasiun Tanjung Priok. Hal ini dapat disimpulkan bahwa, memang daerah yang berpeluang banjir adalah di daerah Tanjung Priok. Sedangkan yang berpeluang kecil terjadi banjir di Stasiun Kemayoran. 
Perlu penelitian yang lebih komprehensif untuk melihat pendugaan curah hujan ekstrim, karena parameter pada sebaran yang mengakomodir nilai ekstrim bisa saja tidak stasioner. Ini berarti parameter-parameter tersebut dapat dipengaruhi oleh suatu peubah penjelas yang mungkin saja dapat memperbaiki model dari pendugaan.

\section{DAFTAR PUSTAKA}

Coles, S. (1993). Regional Modelling of Extreme Storms via Max-Stable Processes. Journal of the Royal Statistical Society Series B. , 55: 797-816.

Coles, S. (2001). Improving the analysis of extreme wind speeds with information sharing models. Notes de Institut Pierre Simon Laplace, 11: 23-34.

Coles, S., \& Tawn, J. (1996). A Bayes analysis of extreme rainfall data. Applied Statistics, 45: 463-478.

Gilli, M., \& Këllezi , E. (2006). An Application of Extreme Value Theory for Measuring Financial Risk. Computational Economics, 27: 207-228.

Hosking, J., \& Wallis, J. (1987). Parameter and quantile estimation for the generalized . Technometrics, 29: 339-349.

Nelder, J., \& Mead, R. (1965. ). A simplex method for function minimization. Computer Journal, 7: 308-313.

Tawn, J. (1988). Bivariate Extreme Value Theory: Models and Estimation. Biometrika, 75:397415. 